\title{
Oscillation Modes of Weld Pool in Stationary GTA Welding Using Structure Laser Method
}

\author{
Xingpei Wu' ${ }^{1}$, Jiankang Huang ${ }^{1 *} \mathbb{C}$, Jing He $\mathrm{e}^{2^{*}}$, Shien Liu' ${ }^{1}$ Guangyin $\mathrm{Liu}^{3}$ and Ding Fan ${ }^{3^{*}}$
}

\begin{abstract}
Researchers have recently attempted to monitor pool oscillations using the three-dimensional laser vision method. However, the deficiency of simulation software will result in significant capital expenditure. Both simulations and experiments are performed in this study, and the Bessel equation is used to analyze the oscillation mode of a weld pool. The laser dot matrix images of $(0,1),(1,1),(2,1)$, and $(0,2)$ oscillation modes at different times are obtained via structured laser optical measurement simulation. The oscillation mode of a stationary gas tungsten arc weld pool is analyzed based on laser dot matrix images obtained from a structure laser experiment. Results show that the simulated laser dot matrix images are consistent with the experiment results. The oscillation mode of the weld pool can be recognized based on the laser dot matrix image. This study not only provides conditions for assessing the penetrating state of a weld pool, but also enable a further understanding of the oscillation mode of a weld pool and the development of more effective observation methods and measurement tools to effectively control and improve welding quality.
\end{abstract}

Keywords: Weld pool surface, GTA welding, Bessel function, Oscillation mode, Geometric optics

\section{Introduction}

Gas tungsten arc (GTA) welding is a form of fusion welding, where an electric arc is applied to the surfaces of parts to melt and join parts [1]. The weld pool contains abundant information regarding the change in the physical state during welding and significantly affects the welding result. The surface shape of the weld pool directly affects the appearance and internal quality of the weld. Many recent studies have focused on the stability of the weld pool size, which is crucial to the weld quality.

In recent years, researchers have established mathematical models to analyze and measure the surface deformation of weld pools. Wu et al. [2] were the first to perform the numerical simulation of fluid flow and

\footnotetext{
*Correspondence: sr2810@163.com; hejing0229@gmail.com; fand@lut.cn 1 School of Materials Science and Engineering, Lanzhou University of Technology, Lanzhou 730050, China

${ }^{2}$ Department of Mechanical Energy Engineering, Southern University of Science and Technology, Shenzhen 518055, China

${ }^{3}$ State Key Laboratory of Advanced Processing and Recycling of Non-Ferrous Metals, Lanzhou University of Technology, Lanzhou 730050, China
}

heat flow in a weld pool, build a model to process fluid flow and temperature field in fully penetrated GTA weld pools, and deduce the calculation formula of surface distortion of weld pools using hydrodynamic theory. To improve welding quality and overcome the limitations of GTA welding, Maruo et al. [3] investigated the relationship between the oscillation frequency and oscillation mode of a circular weld pool; Palani et al. [4] investigated the effects of pulse parameters on arc stability, welding quality, weld morphology, and geometry parameters of welds to obtain higher consistency in the application of robotics and automation in welding; Narang et al. [5] established a fuzzy logic model to predict the shape and profile characteristics of HAZ macrostructure area and GTA pool geometry, thereby avoiding expensive and time-consuming experiments; $\mathrm{He}$ et al. [6] and $\mathrm{Lu}$ [7] used finite element analysis software to analyze the threedimensional surface of welding pools and established a mathematical model to correlate the fluid flow and heat transfer of welding arcs and weld pools; Hirata et al. [8] developed a three-dimensional weld pool flow model 
with a free surface, used the volume-of-fluid method to monitor changes in the surface shape of a weld pool with time, and the continuous surface force method to calculate the tension produced by the surface deformation of the weld pool; Chen et al. [9] introduced identification and intelligent models into weld pool dynamics during pulsed GTAW.

In the actual welding process, optical measurement technology is primarily used, e.g., the structured light three-dimensional visual measurement [10], shape from shading [11], and binocular stereo vision methods [12]. In numerical simulations, the finite element analysis method and other numerical simulation software [13-15] are primarily used. Satonaka et al. [16] measured the free surface of a weld pool using optical and image analysis methods. Saeed et al. [17] proposed a method to extract surface information, such as pool depth from captured images using calibrated charge coupled device (CCD) sensors and structured light, and the presented system can automatically measure and monitor the weld pool surface. Liu et al. [18] proposed a three-dimensional surface control system for a weld pool based on an intelligent response model of human welders, which provided a basis for promptly transforming the intelligence of skilled welders into a robot welding system. Lu et al. [19] established a framework for developing a novel robust sensing and control system to accommodate the depth of the weld pool surface; it can function under different manufacturing conditions and achieve both high speed and stability when the targeted range of manufacturing conditions is wide.

Among them, structured laser optical measurement primarily uses a combination of optical principles, visual measurement technology, and image processing methods to obtain the three-dimensional data of objects. Because of its non-contact, high precision, high resolution, and portability characteristics, it has become the focus of research locally and internationally. Yoo et al. [20] conducted an experimental study regarding the oscillation of a weld pool that is suitable for the geometry measurement of the weld pool through an arc voltage and light emission during GTA welding. They discovered the characteristics of pool oscillation signals in full and transition penetration pools. Saeed et al. [21] and Wang [22] proposed a new three-dimensional weld pool calculation method based on laser specular reflection and developed it into three-dimensional measurement technology to achieve accurate measurements to reconstruct the pool surface based on the reflection law. Liu et al. [23] constructed a novel machine vision system using structured laser to measure the geometric dimensions of the surface of a three-dimensional weld pool in real time and presented a predictive control algorithm for automatic welding. Song et al. [24] investigated an image processing algorithm after a dot matrix laser pattern was reflected from the weld pool surface and obtained the data required for simulation. The oscillation mode of the stationary GTA weld pool was analyzed based on laser dot matrix images and simulation results. The findings will facilitate the further development of welding technology for effectively controlling and improving welding quality. Huang et al. [25] used laser vision sensing technology to observe the surface of GTA weld pools and proposed a mathematical model that correlated the incident ray, reflected ray, as well as the screens and surfaces of weld pools based on structured laser specular reflection. Their study enabled the use of laser vision to measure the surface of weld pools more accurately and rapidly.

Rebuilding the three-dimensional shape of a pool surface not only provides experimental verification for the numerical simulation of the welding thermal process, but also provides a solid foundation for the intelligent control of the welding process, which is vital to engineering applications. COMSOL Multiphysics affords high efficiency in terms of computing performance as well as unique multifield full coupling analysis capability; hence, it can ensure the high accuracy of numerical simulations [26]. In this study, the oscillation modes of the weld pool were analyzed based on the Bessel equation. The laser dot matrix images of $(0,1),(1,1),(2,1)$, and $(0,2)$ oscillation modes at different times were obtained via structured laser optical measurements and simulations of different weld pool surface morphologies.

\section{Weld Pool Surface and Circular Membrane Oscillation}

\subsection{Observation Experiment of Weld Pool Surface}

The geometric relationships of each component of the measurement system are shown in Figure 1(a). The observation system of the weld pool surface in stationary GTA welding is primarily composed of a structure laser reflection imaging system and a laser vision acquisition system. The laser was placed in the $x-z$ plane, which was aligned $45^{\circ}$ to the workpiece horizontally and placed $17.1 \mathrm{~mm}$ away from the torch. The imaging plane was aligned $45^{\circ}$ to the workpiece. The distance between the center point and workpiece was $11.32 \mathrm{~mm}$, and the distance between the camera and workpiece was $48.08 \mathrm{~mm}$. The laser had a rated voltage (direct current, DC) of $3 \mathrm{~V}$, power of $200 \mathrm{~mW}$, and wavelength of $650 \mathrm{~nm}$. The laser vision acquisition system was primarily composed of a CCD industrial camera behind an imaging plane, with a spectral response of 340-1030 $\mathrm{nm}$ and a signal-to-noise ratio of $38 \mathrm{~dB}$. In Figure 1(b), the geometric relationship of the system is shown more 


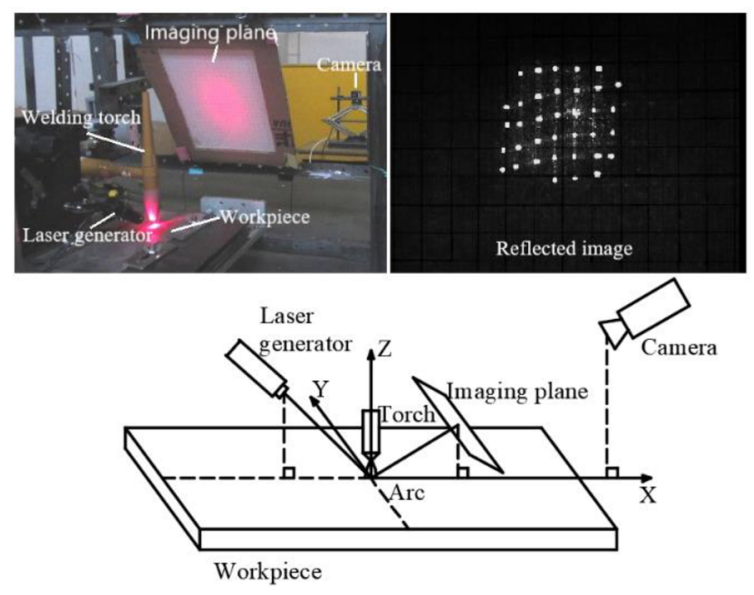

(a)

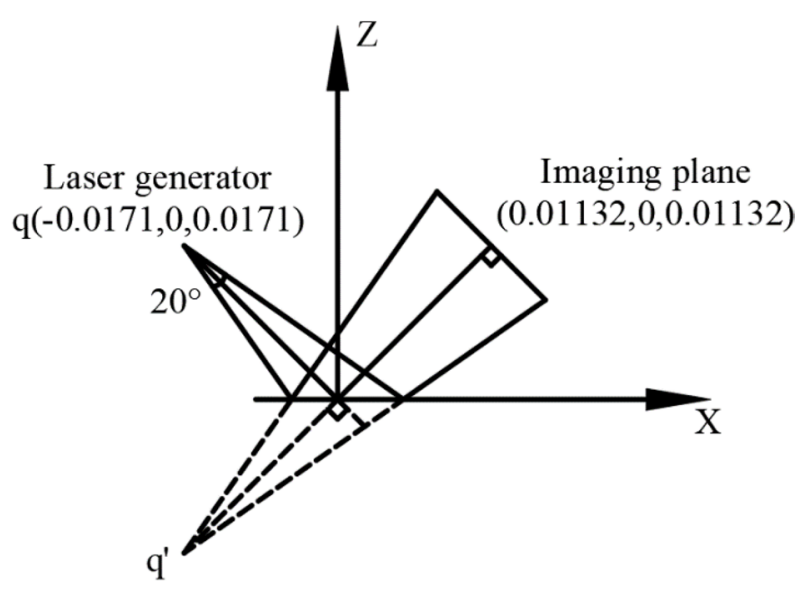

(b)

Figure 1 Schematic diagram of test system

specifically such that the correlation transformation can be simplified and the weld pool behavior described more effectively.

Stationary GTA welding was conducted to observe the weld pool surface based on the test system. A 304 stainless steel plate measuring $125 \mathrm{~mm} \times 50 \mathrm{~mm} \times 3$ $\mathrm{mm}$ was used in the experiment. The welding current was $70 \mathrm{~A}$, and the argon flow was $10 \mathrm{~L} / \mathrm{min}$. Based on the welding process parameters, the oscillation of the weld pool was captured at $1000 \mathrm{f} / \mathrm{s}$ using a high-speed camera during welding. After processing the video image frame by frame, a typical image of the laser grid was selected, as shown in Figure 2. It was observed that the number of adjacent laser points in Figure 2(a)-(c) increased gradually, the distance between laser points increased gradually, the shape of the midpoint array in Figures $2(\mathrm{~d})-(\mathrm{g})$ did not change significantly, the midpoint array in Figures $2(\mathrm{~h})-(\mathrm{k})$ began converging to the middle, and the midpoint arrays in Figure 2(l) almost accumulated.

When the pool was oscillated by excitation, the oscillation amplitude of the weld pool surface was small, but the laser reflection angle caused by the pool oscillation changed significantly. The matrix on the imaging plane exhibited a good optical amplification effect on the weld pool oscillation. The arc radiation intensity decayed off squarely with the increase in distance, and the laser intensity did not decrease with the change in distance. An image screen was placed at the appropriate location from the torch to receive the amplified reflected laser stripe signal. Under the joint action of surface tension, arc pressure, electromagnetic force, and buoyancy, concave and convex weld pool surfaces will appear.

\subsection{Circular Membrane Oscillation and Bessel Function}

If the weld pool surface is regarded as a two-dimensional membrane with a radius of $l$ and a fixed periphery, as shown in Figure 3, it will fluctuate and vibrate owing to the arc force and surface tension. Additionally, it will be affected by the boundary conditions, which exhibit the following forms:

$$
\left\{\begin{array}{l}
u(l, \theta, t)=0, \\
u(r, 0, t)=u(r, 2 \pi, t) .
\end{array}\right.
$$

This type of resonance is similar to a standing wave, i.e., the eigenfrequency of the resonance appears only on some predetermined values. Because the problem is two dimensional, it is solved in a polar coordinate system. The two-dimensional wave equation can be expressed as a partial differential equation in the form of polar coordinates, as follows:

$$
\begin{aligned}
& \frac{1}{V^{2}} \frac{\partial^{2} u}{\partial t^{2}}=\frac{1}{r} \frac{\partial}{\partial r}\left(r \frac{\partial u}{\partial r}\right)+\frac{1}{r^{2}} \frac{\partial^{2} u}{\partial \theta^{2}}+f, \\
& c=V^{2}=\frac{T}{\rho},
\end{aligned}
$$

where $c$ is the diffusion coefficient, $V$ the propagation velocity of the wave that depends on the membrane surface tension and density, and $f$ the source term representing the supply or consumption of dependent variables throughout the entire physical field. When $f=0$, the circular membrane is vibrated by a free surface.

Let $u(r, \theta, t)=z(r, \theta) T(t)$ and $Z(r, \theta)=Z(r) \phi(\theta)$ based on the separation of variables. Therefore, the partial 


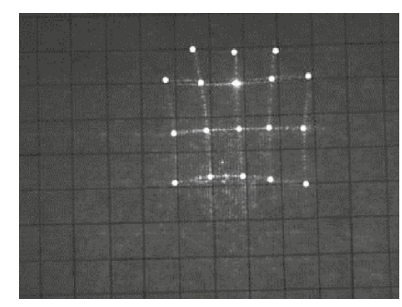

(a)

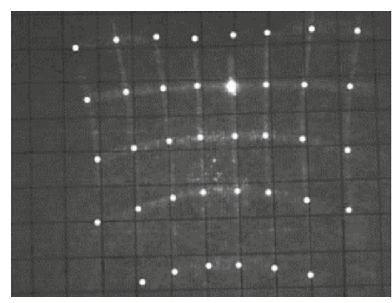

(e)

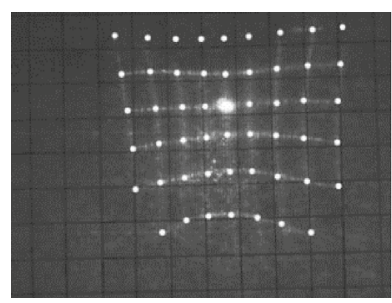

(i)

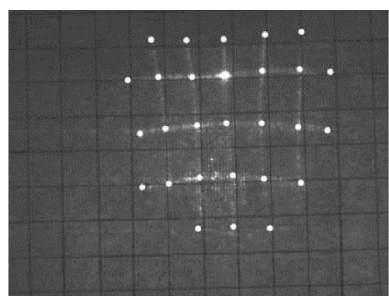

(b)

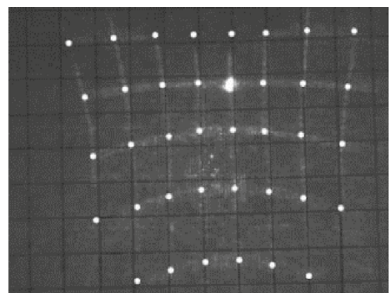

(f)

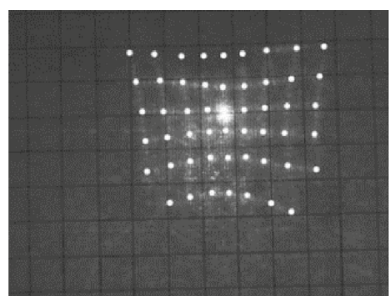

(j)

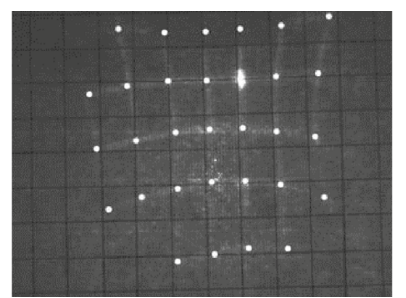

(c)

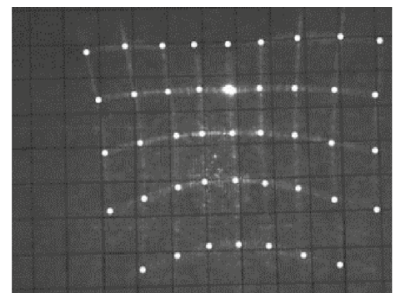

(g)

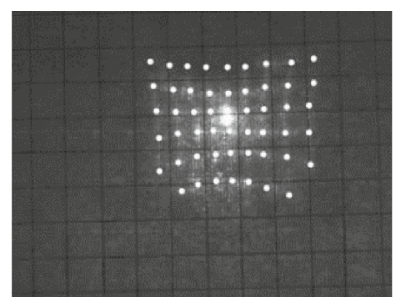

(k)

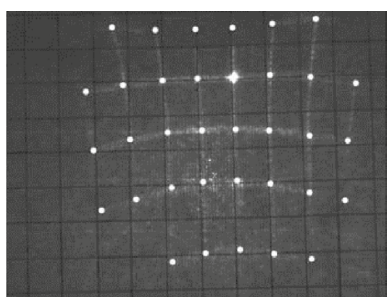

(d)

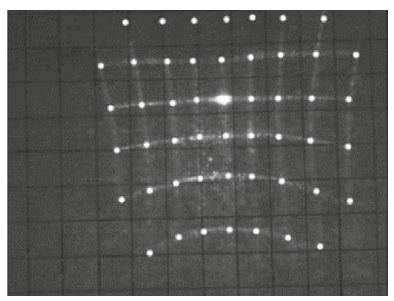

(h)

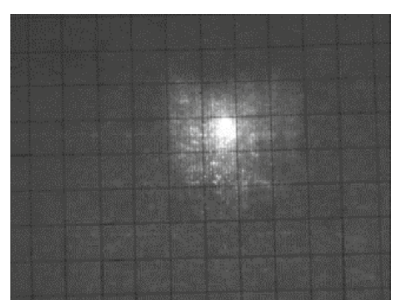

(l)

Figure 2 Laser dot matrix images at 70 A during GTA welding

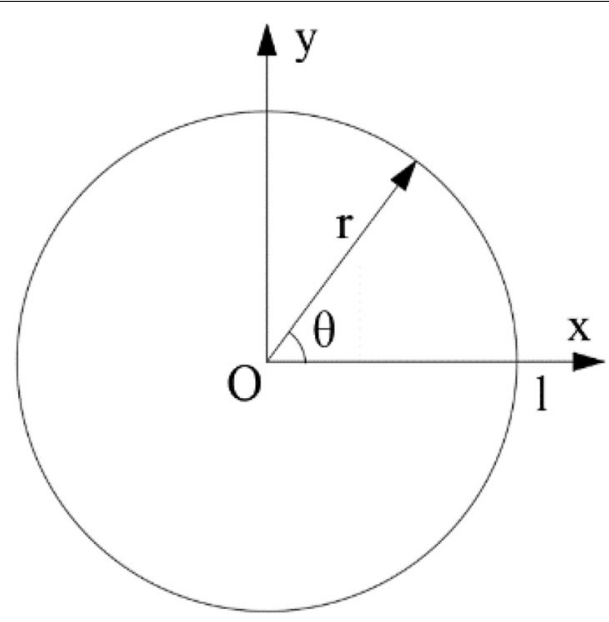

Figure 3 Transverse oscillation of circular membrane differential equation is transformed into the following ordinary differential equations:

$$
\begin{aligned}
& \frac{\mathrm{d}^{2} \phi}{\mathrm{d} \theta^{2}}+n^{2} \phi=0, \\
& \frac{\mathrm{d}^{2} z_{n}}{\mathrm{~d} r^{2}}+\frac{1}{r} \frac{\mathrm{d} z_{n}}{\mathrm{~d} r}+\left(k^{2}-\frac{n^{2}}{r^{2}}\right) z_{n}=0 .
\end{aligned}
$$

The solution of Eq. (4) can be written in the form

$$
\phi(\theta)=c_{1} \sin (n \theta+\varphi) .
$$

Eq. (5) is Bessel's equation, where $k=\frac{\omega}{V}$; its general solution is

$$
Z_{0}(r)=c_{2} J_{n}(k r)+c_{3} N_{n}(k r),
$$

where $J_{n}(k r)$ and $N_{n}(k r)$ are Bessel functions of the first and second kinds, respectively. Assume that $Z_{0}(0)$ should be bounded, but $N_{n}(0)=\infty$ and $c_{3}=0$. 
From the boundary condition shown in Eq. (1), $Z_{0}(l)=0$ can be obtained, and simplifying Eq. (7) yields

$$
J_{n}(k l)=0 .
$$

If $\mu_{n m}$ is the $m$ th positive zero point of the Bessel functions of the first kind, then $k_{n m}=\frac{\mu_{n m}}{l}$ is the eigenvalue of Eq. (8); therefore, the eigenfrequency of the membrane can be written in the form

$$
\omega_{n m}=\mu_{n m} \frac{V}{l} .
$$

The oscillation mode corresponding to $\omega_{n m}$ can be expressed as

$$
Z_{n m}(r, \theta)=J_{n}\left(\mu_{n m} \frac{r}{l}\right) \sin (n \theta+\varphi) .
$$

$J_{n}\left(\mu_{n m} \frac{r}{l}\right)$ corresponds to the nodal diameter of the membrane, and $\sin (n \theta+\varphi)$ corresponds to the nodal circle of the membrane. The combination of the nodal diameter and nodal circle of the membrane can be used to describe the shape of a circular membrane surface.

If the radius is one, then the solution type and normalization of $J_{n}\left(\mu_{n m}\right)$ are defined as follows: The function can be defined using the Taylor-series expansion around $\mu_{n m}=0$, i.e.,

$$
J_{n}\left(\mu_{n m}\right)=\sum_{V=0}^{\infty}(-1)^{V} \frac{1}{V ! \Gamma(n+V+1)}\left(\frac{\mu_{n m}}{2}\right)^{n+2 V} .
$$

The Bessel functions of the first kind is shown in Figure 4. As shown, when $\mu_{n m}$ increased, $J_{n}\left(\mu_{n m}\right)$ exhibited oscillation, which resembled the cosine or sine wave. However, the amplitude of the wave decay was similar to the negative power of $\mu_{n m}$ (Table 1 ).

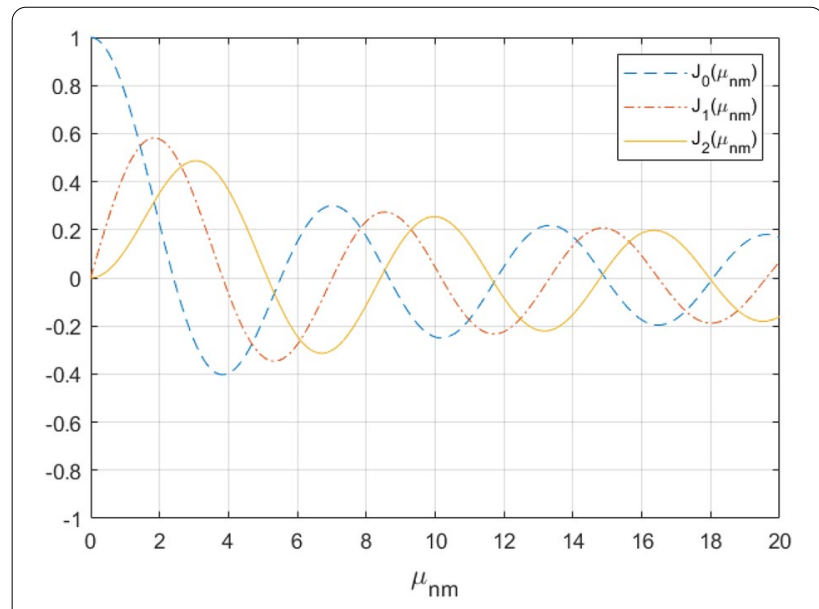

Figure 4 Plot of Bessel functions of first kind
Table 1 First five zero points of $J_{0}(x), J_{1}(x)$, and $J_{2}(x)$

\begin{tabular}{llllll}
\hline $\boldsymbol{m}$ & $\mathbf{1}$ & $\mathbf{2}$ & $\mathbf{3}$ & $\mathbf{4}$ & $\mathbf{5}$ \\
\hline$\mu_{0 m}$ & 2.40483 & 5.52008 & 8.65373 & 11.7915 & 14.9309 \\
$\mu_{1 m}$ & 3.83171 & 7.01559 & 10.1735 & 13.3237 & 16.4706 \\
$\mu_{2 m}$ & 5.13562 & 8.41724 & 11.6198 & 14.7960 & 18.9801 \\
\hline
\end{tabular}

For any shape of the weld pool, the number of nodal circles in the $\theta$ direction is $m$, and the number of nodal diameters in the radius direction is $n$; these two parameters jointly determine the inherent oscillation mode of the weld pool. Simple standing waves such as sine and cosine functions yield various waveforms, as shown in Table 2 . The four typical oscillation modes are the $(0,1)$, $(1,1),(2,1)$, and $(0,2)$ modes.

The natural frequency of the weld pool can be expressed as

$$
\omega_{0}=k_{n m 0} \frac{\sqrt{c}}{R} .
$$

The diffusion coefficient $c$ is associated closely to the surface tension, gravity, geometric size of the pool, and penetration of the pool.

The oscillation of the weld pool can be categorized into three responses based on the initial internal and external conditions: (1) Zero input response, no external force applied, and oscillation of an initial position on the pool surface; (2) in the zero-state response, the initial state of the pool is zero, and the force is exerted from the outside (also known as forced oscillation); (3) the full state response contains an initial state, and an external force is exerted.

When the source term of the two-dimensional wave shown in Eq. (2) is not zero, it represents the forced oscillation of the pool, such as the periodic external force

$$
f=A \cos (\omega t),
$$

where $A$ is the amplitude, $\omega$ the angular frequency, and $t$ the time. When the source term is added, the typical stationary pool oscillation in the time domain appears.

When the weld pool increases to a certain size, the inherent oscillation frequency of the weld pool changes and become equivalent to the sinusoidal frequency in the variable current; at this time, the pool resonates [27]. In the simulation, it was discovered that when the pool reached the resonance point, the pool gradually left the resonance point, and the pool oscillation decelerated gradually. This reflects the rapid release of system energy after the pool had oscillated, resulting in a departure from the resonance point. It has been proven that the frequency of the resonance point corresponds directly to 
Table 2 Four typical modes of circular membrane oscillation

\begin{tabular}{|c|c|c|c|c|}
\hline & $(0,1)$ & $(1,1)$ & $(2,1)$ & $(0,2)$ \\
\hline \multicolumn{5}{|c|}{ 2-D image } \\
\hline \multicolumn{5}{|c|}{ 3-D image } \\
\hline \multirow[t]{9}{*}{ feature } & Upper and lower & Oscillation of left and & The oscillation of the & The center and the \\
\hline & oscillations with the & right antinodes & opposite antinode in & outer edge of the \\
\hline & center of the membrane & separated by one & the same direction and & membrane vibrate \\
\hline & as the antinode. & diameter node passing & the adjacent antinode in & backwards with the \\
\hline & & through the center of & the opposite direction, & largest antinode at the \\
\hline & & the membrane & which is divided by & center of the membrane \\
\hline & & & two diameter nodes & \\
\hline & & & passing through the & \\
\hline & & & center of the membrane & \\
\hline
\end{tabular}

the pool size. The main frequency of the pool oscillation was the same as that of the metal transition. This is analogous to forced vibration [28].

\section{Modeling Simulation and Results}

\subsection{Modeling}

The structure of the laser reflection imaging simulation system was constructed in COMSOL, as shown in Figure 5 , and ray tracing technology in a geometrical optics module was used to accurately trace the rays.

First, based on the state of the weld pool, geometric size, and properties of liquid metals, a mathematical model of the wave equation was established in the mathematical interface based on Eq. (2). Subsequently, the source item was set, where its frequency was greater than or equal to the eigenfrequency of the weld pool. Transient simulation was performed to obtain and export the pool oscillation three-dimensional grid file for the desired mode. Second, the "geometric optics" module

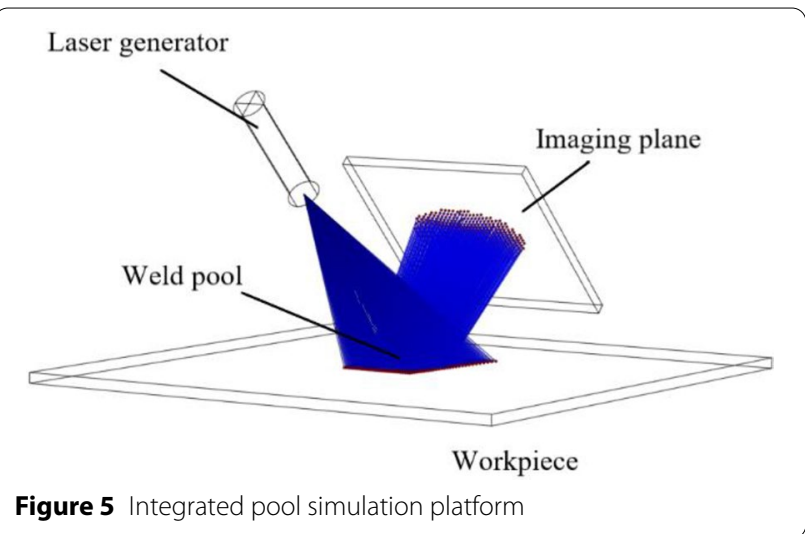

was opened to mesh the pool and imaging plane. Third, a laser generator composed of a $30 \times 30$ laser dot matrix was formed via "grid release" technology, and the emitted light was irradiated to the weld pool. The reflected laser 
was "frozen" when it reached the imaging plane, and a built-in virtual camera can be used to obtain the threedimensional matrix images of the weld pool.

Simulation results on convex, concave, and plane surfaces as well as the simulation parameters are shown in Table 3.

The simulation shows that when the structure laser was reflected onto the concave surface, the distance between the points decreased because of the focus, and the diameter of the imaging plane decreased. Because of the scattered light on the convex surface, the distance between the points and the diameter of the imaging plane increased.

Regardless of the change in the curvature, the number of points reflected in the imaging plane did not change. This implies that the number of points is related to the diameter, and the surface shape can be analyzed using the matrix image.

By performing mathematical modeling, the relevant physical properties of metal materials can be built into the software; this can significantly improve the efficiency and accuracy of the simulation. Mainstream structural light analysis and numerical simulation methods can be combined organically. The complex process in a weld pool can be visualized using structural laser measurement technology. The simulation of the process can significantly reduce all types of errors and uncertainties in the test, facilitate further improvements of defects in the measurement method, optimize the equipment configuration, realize the full potential and advantages of the structural laser method, capture the dynamic details of the weld pool oscillation process, and enable basic investigations of welding technology to effectively control and improve welding quality.

\subsection{Results}

During welding, it is very difficult to observe the threedimensional morphology of the GTA weld pool surface because of adverse factors such as rapid changes on the pool surface, splashing, and the arc intensity. Furthermore, electromagnetic interference, high-temperature plasmas, and high-temperature pools are involved during welding. Mechanical and electromagnetic methods are not suitable for obtaining three-dimensional information during welding. The requirement for real-time measurements of the weld pool height necessitates infrared sensing, and X-ray methods cannot be used. An effective processing algorithm is essential to obtain the desired results such that advanced intelligent control strategies can be designed to effectively control the welding quality based on the feedback of weld pool measurements under different process conditions and disturbances. Therefore,

Table 3 Simulation parameters and results

\begin{tabular}{|c|c|c|c|c|}
\hline & Tadius(mm) & Height(mm) & Model & Simulation \\
\hline Concave & 2.1 & -0.06 & & IIIIIIII!! \\
\hline Plane & 2.1 & 0 & & \\
\hline Convex & 2.1 & 0.06 & & \\
\hline
\end{tabular}


the relationship between welding quality measurement and welding quality must be modeled. A high-speed camera was used to capture the laser matrix images of the four oscillating modes on the surface of the weld pool under periodic external forces to verify the simulation results.

\subsection{1 (0, 1) Mode}

The $(0,1)$ mode corresponds to the first zero point of the zero-order Bessel function and comprises two states: convex and concave. The maximum amplitude is located in the middle of the weld pool, as shown in Figure 6(a)(l). A pool is convex when the spacing between the centers of the dot matrix is larger than the edge spacing, and the horizontal and vertical dimensions of the image are close to each other. Meanwhile, a pool is concave when the middle points of the dot matrix are close to each other, the edge spacing is large, and the image's horizontal dimension is larger than the vertical dimension. When the convex curvature is large, the matrix is large; when the concave curvature is large, the matrix is tight. The matrix spacing decreases with time, which indicates that the pool is in the attenuated oscillation state of the $(0,1)$ mode.

The images of the reflective laser grid on the surface of the weld pool were obtained experimentally, as shown in Figure 7. The experimental results were consistent with the simulation results shown in Figure 6. By comparing the simulation results of the weld pool surface, it was discovered that the oscillation mode of the GTA weld pool was the $(0,1)$ mode. Figures $7(a)$ and $(b)$ show that the weld pool surface was convex and concave, respectively.

\subsection{2 (1, 1) Mode}

The $(1,1)$ mode corresponds to the first zero point of the first-order Bessel function. As shown in Figure 8(a)-(l), one direction of the dot matrix exhibited large spacing and occupied a larger area, whereas the other direction exhibited a small spacing and occupied a smaller area. The large sides of the dot matrix indicate a convex weld pool, whereas the opposite direction indicates a concave weld pool. After one period, the scattering direction was

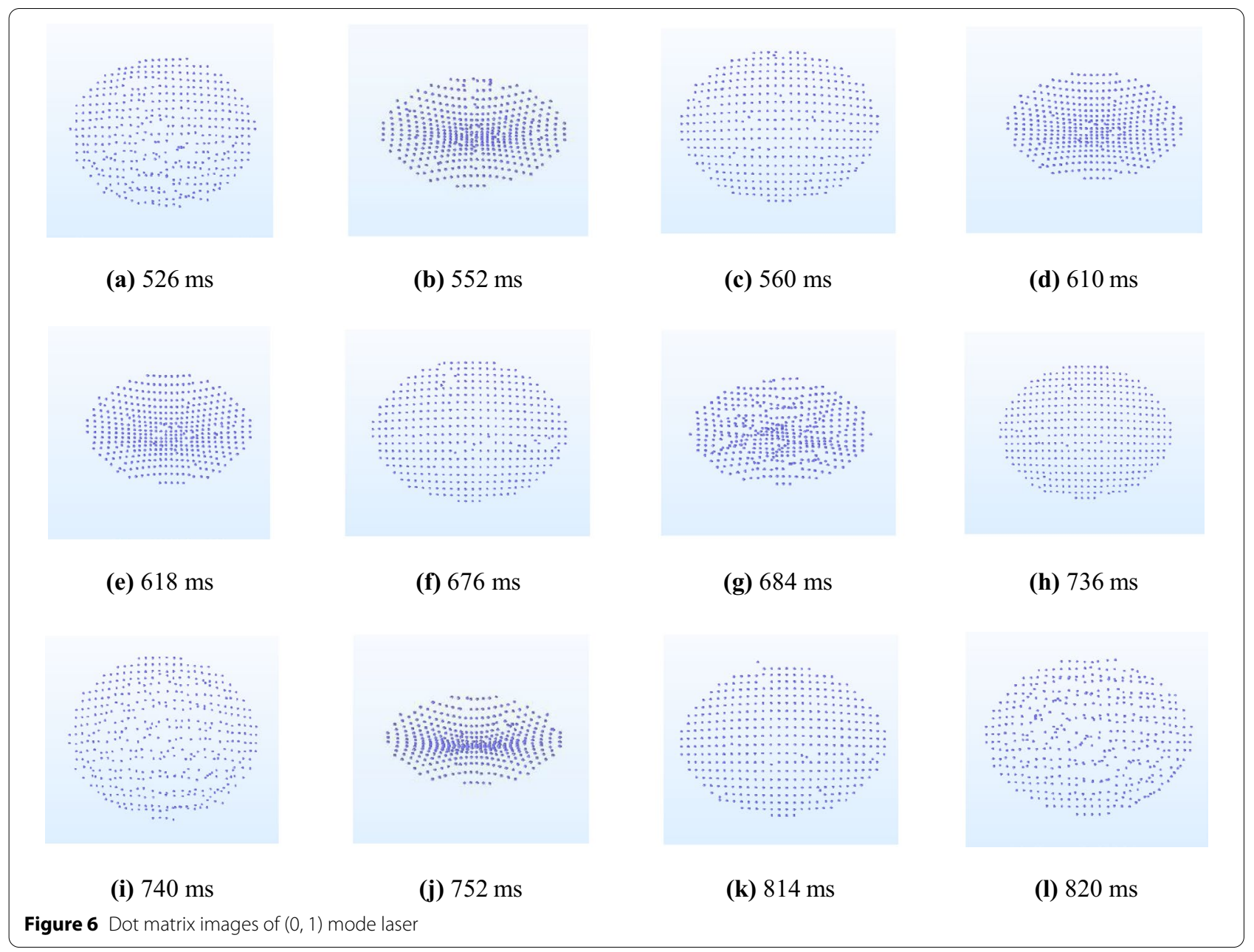




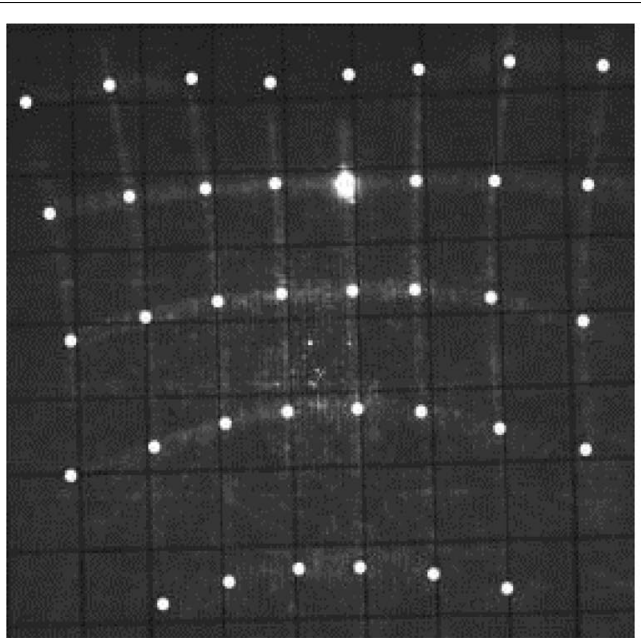

(a)

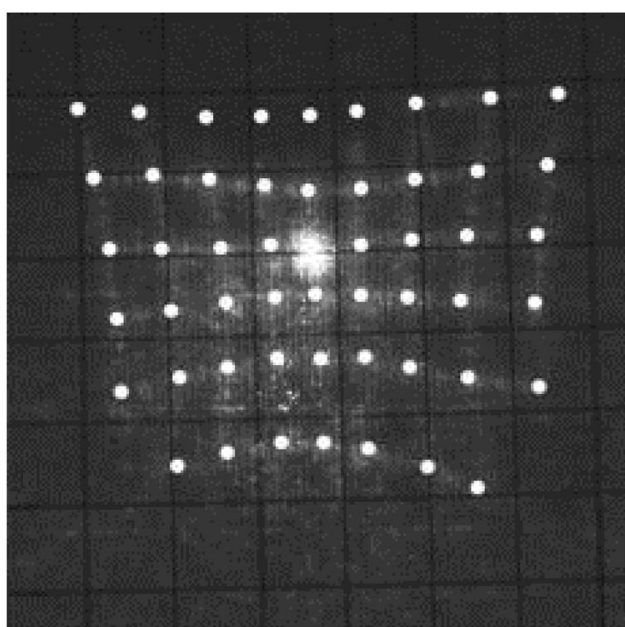

(b)

Figure $7(0,1)$ mode experimental results

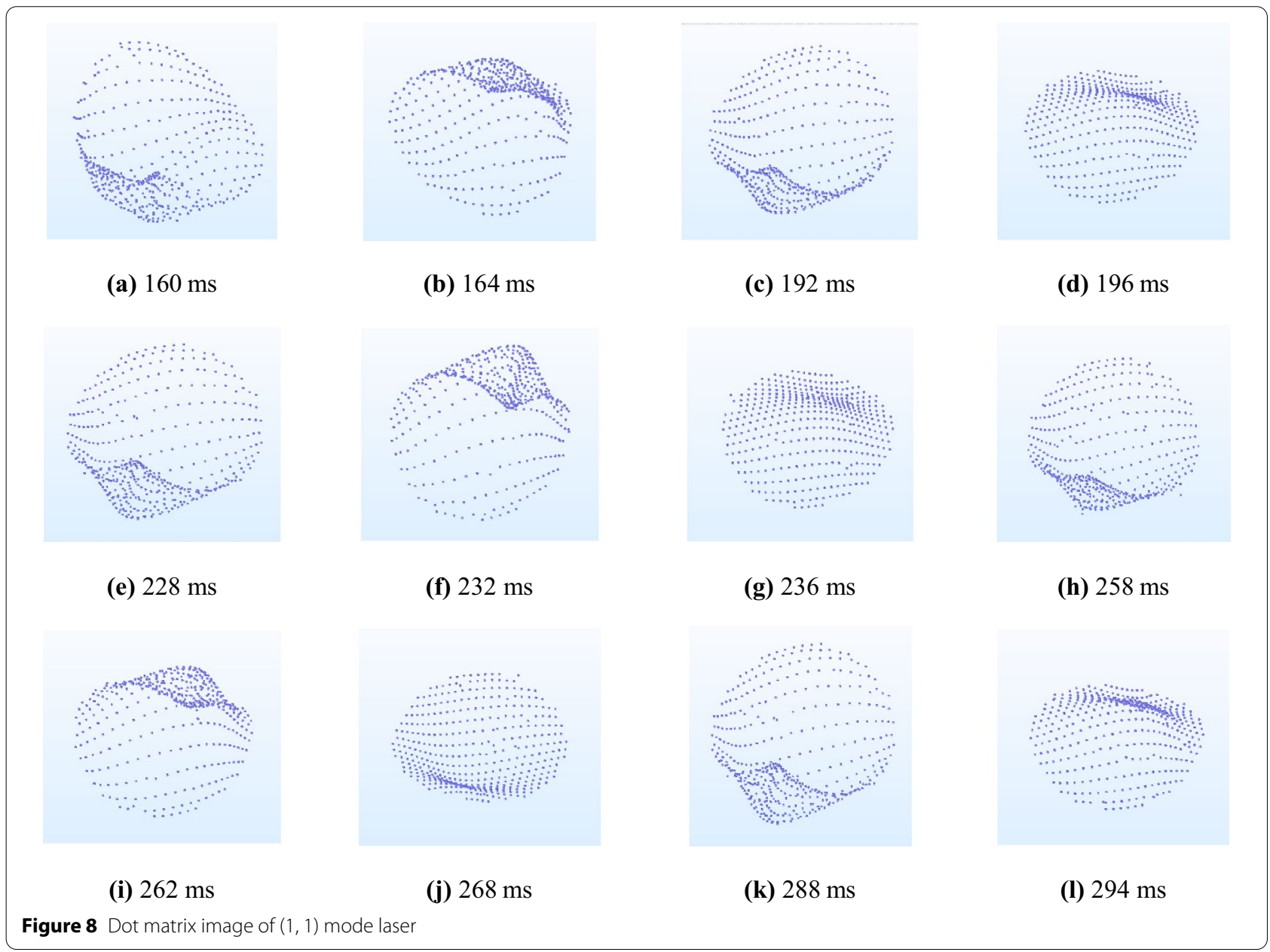


exchanged with that of the compact location. The area occupied by the matrix became gradually smaller than the matrix divergence, indicating that the pool was in the attenuated oscillation state of the $(1,1)$ mode.

Under a pulse current, when the critical penetration was reached, sloshing oscillation occurred and the continuous reflection laser dot matrix appeared as shown in Figure 9. This is consistent with the simulation results shown in Figure 8.

\subsection{3 (2, 1) Mode}

The $(2,1)$ mode corresponds to the first zero point of the second-order Bessel function. As shown in Figure 10(a)(l), the spacing between the two sides of the matrix was large, exhibiting an irregular circle. A narrow and compact matrix was located in the middle of the separation line. The closed matrix at both ends of the separation line showed an irregular triangular area. After one period, the separation line was perpendicular to the original position, and the closed triangle area became a large quasicircle; subsequently, it returned to its original shape, indicating that the pool was in the attenuated oscillation state of the $(2,1)$ mode.

The reflective image obtained in the pulsed GTA welding experiment is shown in Figure 11, and its surface oscillation mode matched the simulation results shown in Figure 10.

\subsection{4 (0, 2) Mode}

The $(0,2)$ mode corresponds to the second zero point of the zero-order Bessel function. As shown in Figure $12(\mathrm{a})-(\mathrm{l})$, the matrix spacing in the middle core area was small, and the outer core area was large. The matrix spacing in the middle large area was large, and a narrow and compact matrix circle was observed near the outer edge. The period of variation changed rapidly, indicating that the pool was in a fast attenuated oscillation state of the $(0,2)$ mode.

The oscillation of the weld pool in full penetration was radially symmetric with respect to the arc axis. The pool oscillation, as shown in Figure 13, can be observed clearly from the reflected laser point characteristics and is consistent with the simulation results shown in Figure 12.

It was observed that as time progressed, the variation in the lattice spacing decreased gradually, indicating that the weld pool oscillation was in a state of attenuation, which is consistent with the experimental phenomenon observed by Wang et al. [29], where the fluctuation amplitude of the weld pool surface decreased as the penetration degree increased.

To achieve real-time and low-cost commercial application using visual sensing technology, Wang [30]] reported that the real-time control of welding requires highspeed and accurate image processing as well as a weld pool reconstruction algorithm. In addition to speed and accuracy, sensor robustness must be improved/assured to monitor the welding process in a various demanding application environments. It was discovered that a $30 \times$ 30 laser matrix can enable the oscillation mode on the weld pool surface to be observed.

\section{Discussion}

To obtain more characteristics of the weld pool oscillation surface shape, researchers have investigated the pool shape under both direct and pulsed currents.

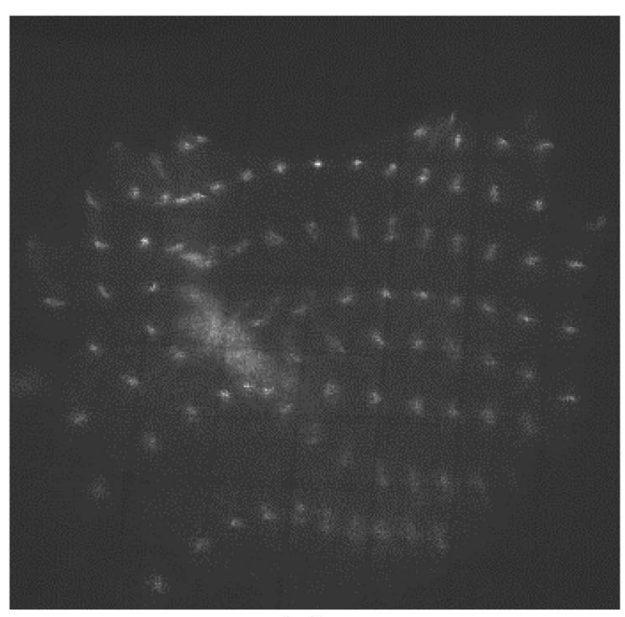

(a)

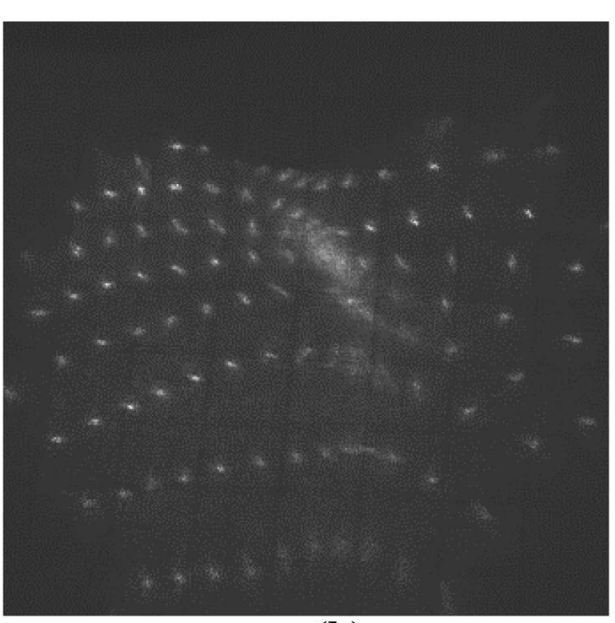

(b)

Figure $9(1,1)$ mode experimental results 


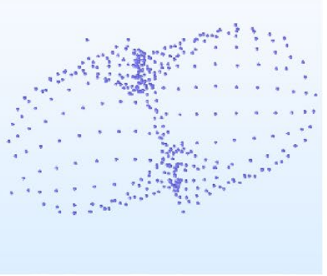

(a) $188 \mathrm{~ms}$

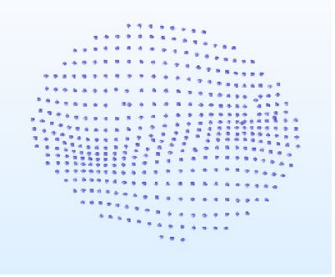

(e) $232 \mathrm{~ms}$

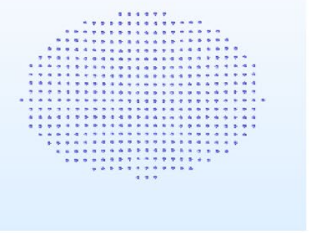

(i) $302 \mathrm{~ms}$

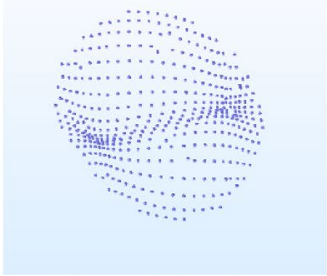

(b) $190 \mathrm{~ms}$

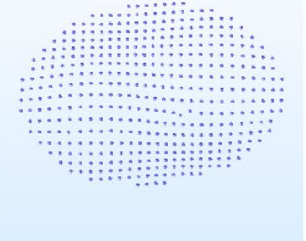

(f) $236 \mathrm{~ms}$

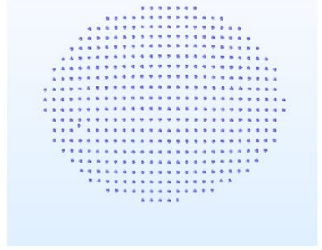

(j) $354 \mathrm{~ms}$

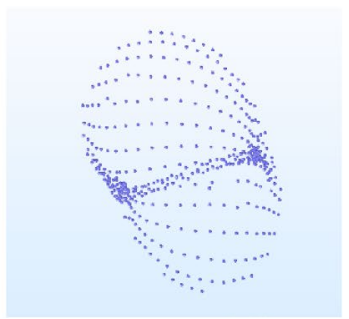

(c) $192 \mathrm{~ms}$

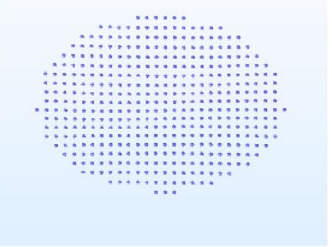

(g) $242 \mathrm{~ms}$

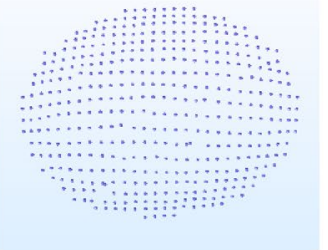

(k) $420 \mathrm{~ms}$

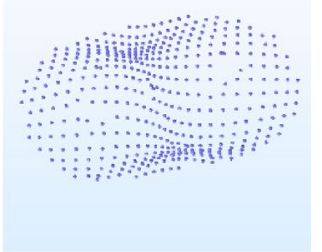

(d) $196 \mathrm{~ms}$

Figure 10 Laser dot matrix image of $(2,1)$ mode

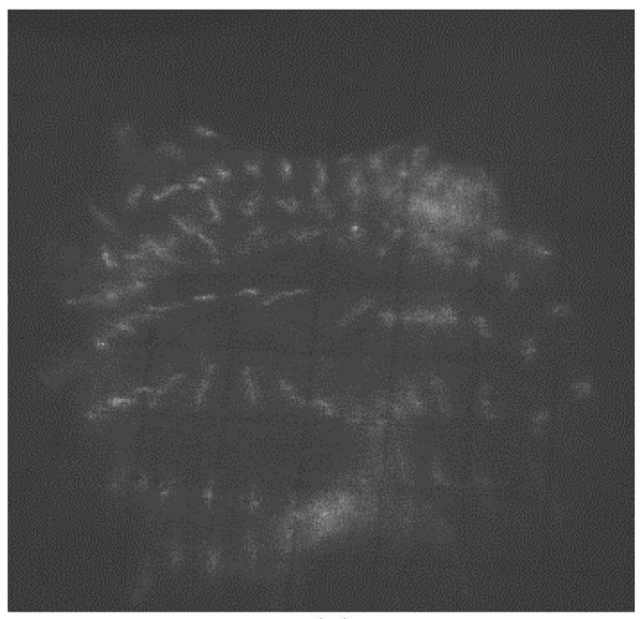

(a)

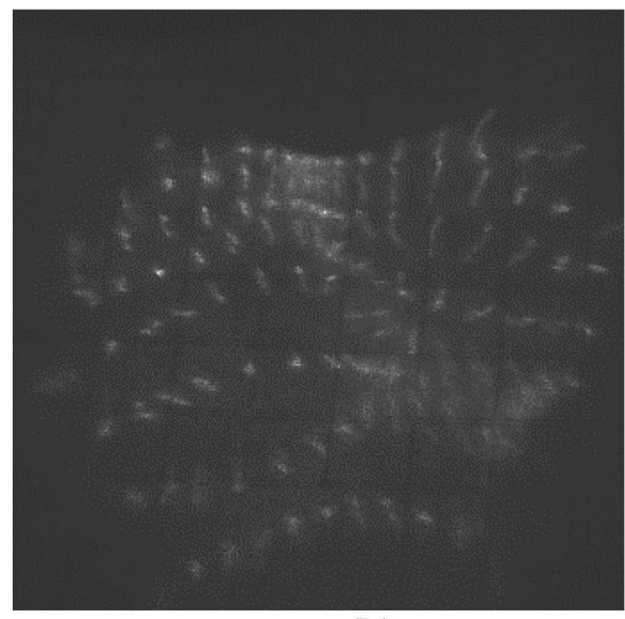

(b)

Figure 11 Experiment results of $(2,1)$ mode 


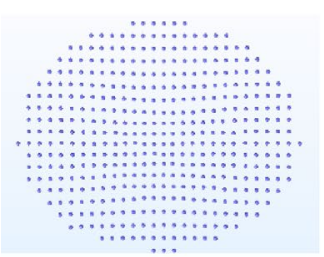

(a) $132 \mathrm{~ms}$

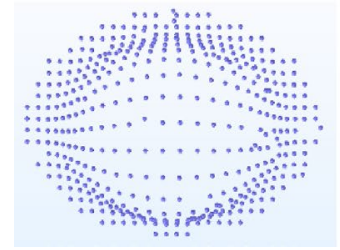

(e) $137 \mathrm{~ms}$

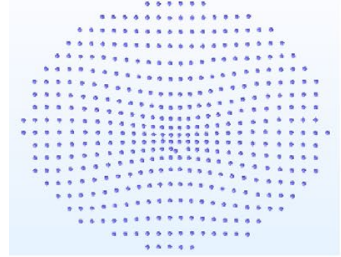

(i) $173 \mathrm{~ms}$

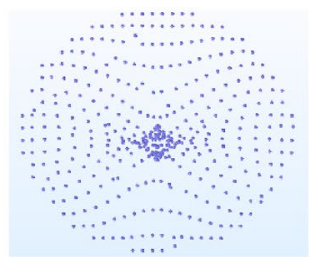

(b) $133 \mathrm{~ms}$

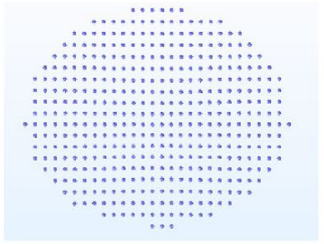

(f) $139 \mathrm{~ms}$

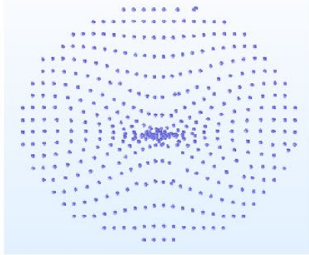

(j) $174 \mathrm{~ms}$

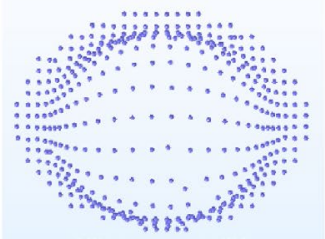

(c) $135 \mathrm{~ms}$

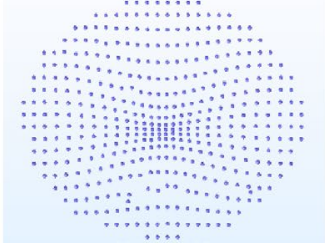

(g) $140 \mathrm{~ms}$

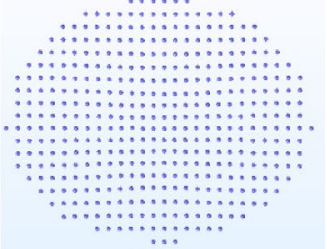

(k) $177 \mathrm{~ms}$

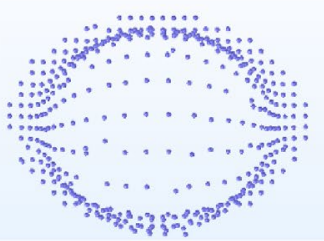

(d) $136 \mathrm{~ms}$

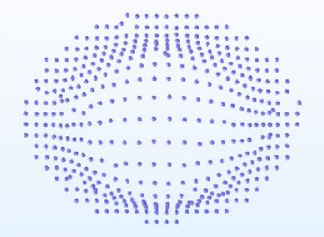

(h) $171 \mathrm{~ms}$

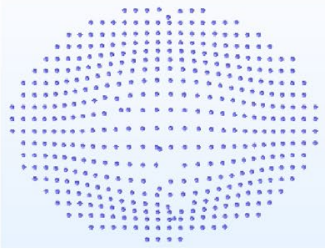

(I) $215 \mathrm{~ms}$

Figure 12 Dot matrix image of $(0,2)$ mode laser

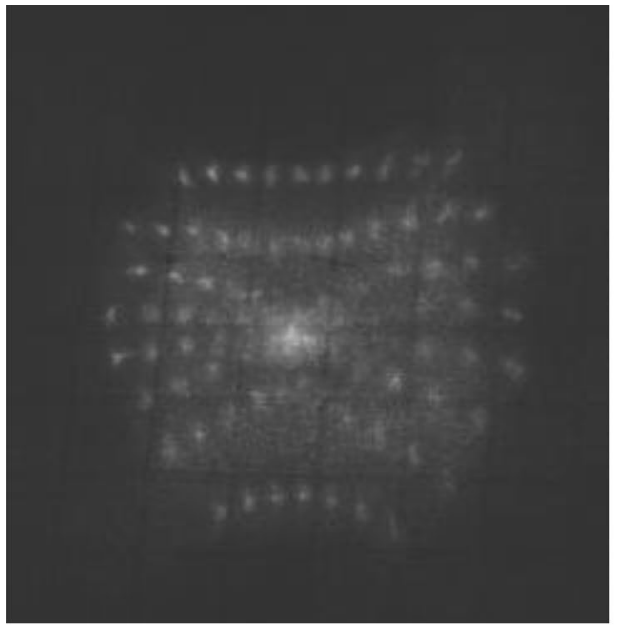

(a)

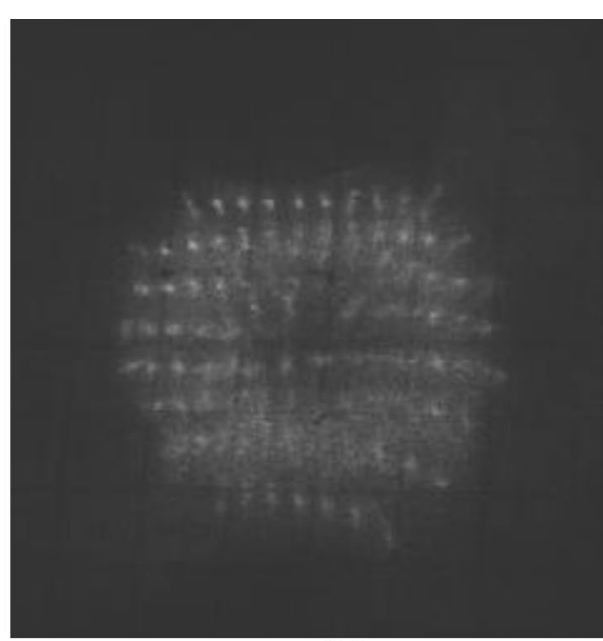

(b)

Figure 13 Experimental results of $(0,2)$ mode

\subsection{Weld Pool Shape under DC and Pulsed GTA Welding} Under the condition of penetration, the change in the height of the upper and lower surfaces of the center of the stationary DC GTA welding pool with time was recorded, as shown in Figure 14. At the beginning of welding, the upper surface of the melting pool was heated, melted, and expanded, thereby resulting in a convex shape owing to the effect of the liquid surface tension. However, the lower surface did not change. At 3.9 s, the weld pool widened, and the workpiece penetrated the weld pool. The 


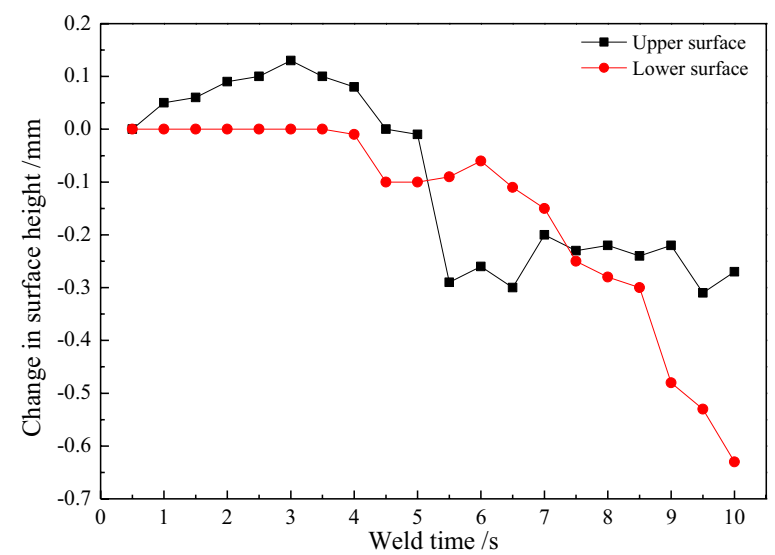

Figure 14 Variation in upper and lower surface heights of stationary DC GTA welding

upper and lower free surfaces collapsed under the action of gravity. From $5 \mathrm{~s}$ to $5.5 \mathrm{~s}$, the change in the upper surface was significant, i.e., from convex to concave. Compared with the change in the upper surface, the change in the lower surface was less obvious. The lower surface first ascended and then descended. Subsequently, when the welding time reached $7.5 \mathrm{~s}$, the variation in the upper and lower surfaces reached the same value. Next, the variation in the height of the upper surface was not obvious, but the variation in the lower surface was significant.

The phenomenon above can be explained as follows: In the first stage, the volume and depth of the weld pool were smaller. Therefore, the effect of surface tension was greater than that of gravity and arc pressure on the weld pool. The weld pool was convex and belonged to the $(0$, 1) mode. In the second stage, as the welding progressed, the temperature in the workpiece increased gradually, the range of the temperature field increased, both the penetration depth and melting width increased, and the free surface deformed more as welding time progressed.
Owing to the arc pressure, the center of the weld pool changed gradually from convex to concave, and the liquid metal expanded radially; hence, it presented a concave image of the $(0,2)$ mode. In the third stage, the weld pool was penetrated, the bottom of the weld pool was no longer under pressure, and gravity was the main force. The liquid metal sagged to a concave surface in the $(0$, 1) mode. The entire weld pool was centrally symmetrical with respect to the torch, and its laser dot matrix image was stable and clear. These three stages developed dynamically in a few seconds; therefore, the laser matrix image was easily recognizable. Furthermore, the $(2,1)$ or $(1,1)$ mode can appear when the current or speed of the welding changes abruptly.

In pulsed GTA welding, when the peak current was applied, the width and depth of the weld pool increased significantly during the peak current period [31]. Additionally, the matrix was fuzzy and aggregated, indicating a concave weld pool surface. When the base current was applied, the laser grid changed from converging to diverging, indicating a convex weld pool surface; however, the weld pool surface continued to fluctuate.

\subsection{The Relationship and Difference between DC and Pulsed GTA Welding}

During the stationary welding process, as shown in Figure 15(a), the electrode axis coincided with the centerline of the weld pool, and the arc was located exactly at the weld pool center. When the liquid metal was supported by the bottom of the weld pool, the weld pool center was symmetrically depressed under the arc pressure, and the liquid metal was pushed radially. Hence, the pool edge was elevated, and the weld pool was similar to the $(0,2)$ mode. When the bottom of the weld pool was no longer supported by the solid metal, as shown in Figure 15(b), the liquid metal at the pool bottom was maintained by surface tension. Owing to the arc pressure and loss of

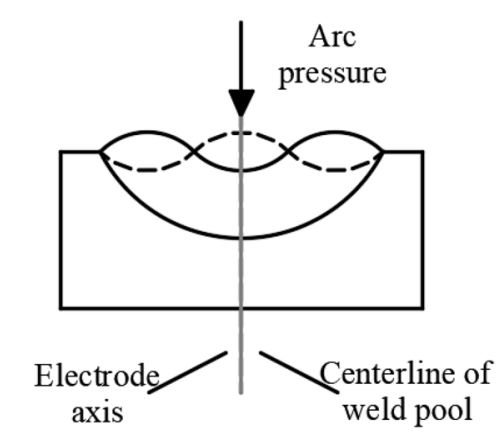

(a)

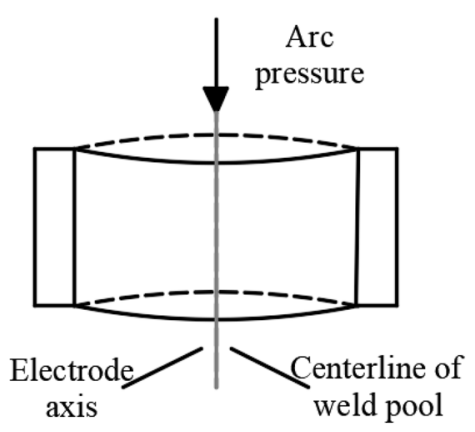

(b)

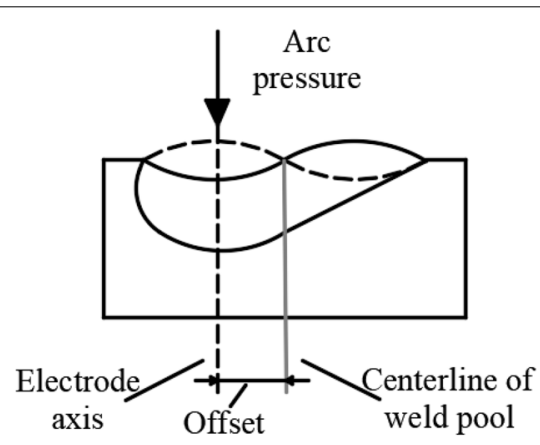

(c)

Figure 15 Different shapes of weld pool surfaces during welding 
solid metal support at the bottom, the upper and lower surfaces of the weld pool were concave, which is similar to the $(0,1)$ mode. This is consistent with the results of Zhang et al. [32].

In most cases, when an offset occurs between the centerline of the weld pool and the electron axis, as shown in Figure 15(c), the metal in the weld pool was pushed easily to the rear part of the weld pool, thereby resulting in an asymmetrical weld pool [33]. This can be represented by the $(1,1)$ mode.

When the torch current was reduced abruptly, the arc pressure at the top of the weld pool was released. The lowest point of the pool surface stretched upward owing to surface tension. The shape of the corresponding weld pool oscillating surface was convex, and the original protrusion changed into the opposite direction. The shape of the pool surface changed, as shown by the dashed line in Figure 15(a)-(c).

The behavior of the weld pool during GTA welding evolved dynamically. The final surface shape depended on the surface tension, gravity, support force of the weld pool wall, and applied arc pressure. The joint action of these factors determines whether the pool is in a quasi-steady or dynamic state. When the weld pool is depressed, the point matrix aggregates; otherwise, the point matrix diverges. By calculating the time interval between two aggregated or divergent laser matrix images, the oscillation period in the pool can be obtained [34].

The difference between the DC and pulsed GTA welding is explained as follows: During DC welding, from the beginning to the penetration, if the welding conditions remain unchanged, then the shape of the pool surface will change non-periodically, lasting several seconds, and the dot matrix image will be clear. Meanwhile, during pulse welding, the shape of the weld pool surface changes periodically, lasting several milliseconds to several hundred milliseconds, and the image is slightly blurred.

However, when the DC welding conditions are abrupt, both DC and pulsed welding can be converted to each other. If the current and speed change abruptly, then the weld pool will undergo short-term periodic changes, and the dot matrix image will be blurred for a short time.

\subsection{Characteristics of Weld Pool Surface}

Different mathematical models have been developed to describe the oscillation modes of the weld pool, as listed in Table 4. The reflection changes in the laser matrix reflect the dynamic changes of the weld pool surface. Three modes of oscillation were clearly observed under different penetrations. The oscillation mode can be described by the first Bessel function, which is consistent with the experimental results.

It was discovered that a one-to-one relationship existed among the shape, eigenvalue, $k_{n m}$, and mode shape of the matrix images. However, the pool oscillation model observed previously was limited to a few types, and (2, 1) models have rarely been investigated owing to limitations imposed by experimental parameters and equipment conditions. Therefore, numerical simulations are necessary for accurately explaining the various oscillation phenomena that may be encountered during welding.

\section{Conclusions}

In this study, the oscillation modes of a weld pool were analyzed based on the Bessel equation, and typical three-dimensional images of the weld pool were simulated. The laser dot matrix images of the $(0,1),(1,1)$, $(2,1)$, and $(0,2)$ oscillation modes at different times were obtained via structured laser optical measurement simulation. The oscillation mode of the stationary

Table 4 Mode shapes of weld pool obtained by different researchers

\begin{tabular}{|c|c|c|c|c|}
\hline & $(0,1)$ & $(1,1)$ & $(0,2)$ & $(2,1)$ \\
\hline$k_{n m}$ & $\frac{4.80}{D}$ & $\frac{7.66}{D}$ & $\frac{11.04}{D}$ & $\frac{10.28}{D}$ \\
\hline \multicolumn{5}{|l|}{ Shapes } \\
\hline Xiao and Ouden (1990 [35]) & $\sqrt{ }$ & - & $\sqrt{ }$ & - \\
\hline Zhang (2016 [36]) & $\sqrt{ }$ & $\sqrt{ }$ & - & - \\
\hline Andersen (1997 [37]) & $\sqrt{ }$ & $\sqrt{ }$ & $\sqrt{ }$ & - \\
\hline Sorensen (1990 [38]) & - & - & $\sqrt{ }$ & - \\
\hline Aendenroomer (1998 [39]) & $\sqrt{ }$ & - & $\sqrt{ }$ & - \\
\hline Ju (2004 [40]) & $\sqrt{ }$ & $\sqrt{ }$ & - & - \\
\hline
\end{tabular}


GTA weld pool was analyzed based on laser dot matrix images. The following conclusions were obtained from this study.

1) The status of the weld pool can be determined using laser dot matrix images. For example, by distinguishing the distribution of concave, convex, and flat surfaces, we can observe the oscillation mode and oscillation frequency of the pool; therefore, non-penetrating and penetrating states can be distinguished from the pool.

2) In stationary DC GTA welding, the oscillation mode is generally in the $(0,1),(0,2)$ mode. In pulsed GTA welding, the arc impact on the weld pool during the peak current phase caused high-frequency oscillations on the surface of the pool, thereby resulting in significant distortions on the pool surface and hence $(1,1),(2,1)$, and $(0,2)$ oscillation modes.

3) Although the laser dot matrix images on the imaging plane changed dynamically, the shape of the weld pool can be recognized based on the laser dot matrix image. The denser the dot matrix emitted by the laser generator, the higher was the measurement accuracy. This observation can be applied to improve structural laser technology.

\section{Acknowledgements}

We are grateful for the technical and financial support provided by the Lanzhou University of Technology, National Natural Science Foundation of China.

\begin{abstract}
Authors' Contributions
XW investigated the welding process using COMSOL and wrote the manuscript; $\mathrm{JH}$ and DF proposed the research project, conceived and designed the study, and revised the manuscript; $J H$ improved the research by theory and revised the manuscript; SL and GL assisted in numerical analysis and experimental verification. All authors read and approved the final manuscript.
\end{abstract}

\section{Authors' Information}

Xingpei Wu is a student at Lanzhou University of Technology, China. His research interests include numerical simulations of the welding process.

Jiankang Huang is currently a professor at Lanzhou University of Technology, China. His research interests include numerical simulations of welding and arc additive manufacturing.

Jing He is a faculty member at Southern University of Science and Technology, China. His research interests include welding processes and additive manufacturing.

Shien Liu is currently a student at Lanzhou University of Technology, China. His research interests include dissimilar metal connections and arc additive manufacturing.

Guangyin Liu is a student at Lanzhou University of Technology, China. His research interests include dissimilar metal connections and numerical simulations of welding.

Ding Fan is currently a professor at Lanzhou University of Technology, China. His research interests include numerical simulations of welding and arc additive manufacturing.

\section{Funding}

Supported by National Natural Science Foundation of China (Grant No. 51205197).

\section{Competing interests}

The authors declare no competing financial interests.

Received: 29 April 2020 Revised: 4 February 2021 Accepted: 25 August 2021

Published online: 19 September 2021

\section{References}

[1] M Kanouff, R Greif. The unsteady development of a GTA weld pool. International Journal of Heat \& Mass Transfer, 1992, 35: 967-979.

[2] C S Wu, Z N Cao, L Wu. Numerical analysis of three-dimensional fluid flow and heat transfer in TIG weld pool with full penetration. Acta Metallurgica Sinica, 1993, 16: 894-895.

[3] H Maruo, Y Hirata. Natural frequency and oscillation mode of weld pool. Japan Welding Society, 1992: 50-54.

[4] P K Palani, N Murugan. Selection of parameters of pulsed current gas metal arc welding. Journal of Materials Processing Technology, 2006, 172: $1-10$

[5] H K Narang, U P Singh, M M Mahapatra, et al. Prediction of the weld pool geometry of TIG arc welding by using fuzzy logic controller. International Journal of Engineering, Science and Technology, 2011, 3: 77-85.

[6] J S He, W Liu, B G Zhang, et al. Numerical simulation on the shape of liquid surface of TIG full-penetrated weld pool. Rare Metals, 2007, 26: 73-76.

[7] F Lu, S Yao, S Lou, et al. Modeling and finite element analysis on GTAW arc and weld pool. Computational Materials Science, 2004, 29: 370-378.

[8] Y Hirata, S Kunishige, T Ohji. 3D numerical model of weld pool oscillation in GTA welding. Japan Welding Society, 2003, 73: 184-185.

[9] S B Chen, J Wu. Modeling methods of weld pool dynamics during pulsed GTAW. Intelligentized Methodology for Arc Welding Dynamical Processes, 2009: 113-162.

[10] H S Song, Y M Zhang. Three-dimensional reconstruction of specular surface for a gas tungsten arc weld pool. Measurement Science \& Technology, 2007, 18: 3751-3767.

[11] Q Y Du, S B Chen, T Lin. Inspection of weld shape based on the shape from shading. The International Journal of Advanced Manufacturing Technology, 2006, 27: 667-671.

[12] CX Zhao, I M Richardson, S Kenjeres, et al. A stereo vision method for tracking particle flow on the weld pool surface. Journal of Applied Physics, 2009, 105: 1-8.

[13] H Park, S Rhee, K Um. Analysis of weld pool flow and shape considering the impact of droplets in GMAW. Journal of Advanced Nursing, 1998, 16: 83-90.

[14] C S Wu, T Zhang, Y H Feng. Numerical analysis of the heat and fluid flow in a weld pool with a dynamic keyhole. International Journal of Heat and Fluid Flow, 2013, 40: 186-197.

[15] Y Satoshi, Y Kensuke, O Kenji. Numerical simulation of weld pool in narrow gap GMA welding. Quarterly Journal of the Japan Welding Society, 2009, 27: 506-516.

[16] S Satonaka. Measurement of free surface of the weld pool by optical method and image analysis. Japan Welding Society, 1984, 2: 3-9.

[17] G Saeed, Y M Zhang. Weld pool surface depth measurement using a calibrated camera and structured light. Measurement Science and Technology, 2007, 18: 2570-2578.

[18] Y K Liu, Y M Zhang. Dynamic control of 3D weld pool surface based on human response model. The International Federation of Automatic Control, 2014, 47: 10640-10645.

[19] W Lu, Y M Zhang. Robust sensing and control of the weld pool surface. Measurement Science and Technology, 2006, 17: 2437-2446.

[20] C D Yoo, R W Richardson. An experimental study on sensitivity and signal characteristics of weld pool oscillation. Transactions of the Japan Welding Society, 1993, 24: 54-62.

[21] G Saeed, M Lou, Y M Zhang. Computation of 3D weld pool surface from the slope field and point tracking of laser beams. Measurement Science and Technology, 2004, 15: 389-403. 
[22] XW Wang. Analysis and modeling of GTAW weld pool geometry. International Conference on Intelligent Computing for Sustainable Energy \& Environment, 2013, 355: 284-293.

[23] Y K Liu, Y M Zhang. Control of 3D weld pool surface. Control Engineering Practice, 2013, 21: 1469-1480.

[24] H S Song, Y M Zhang. Image processing for measurement of threedimensional GTA weld pool surface. Welding Journal, 2007, 86: 323.s-330.s.

[25] J K Huang, J He, X He, et al. Study on dynamic development of threedimensional weld pool surface in stationary GTAW. High Temperature Materials and Processes, 2017: 37.

[26] L Teich, A Hütten, C Schröder. Utilization of COMSOL multiphysics' JAVA API for the implementation of a micromagnetic modeling and simulation package with a customized user interface, 2013.

[27] C L Yang. Detection of surface tension and effect of surface active flux in TIG welding. Journal of Mechanical Engineering, 2000, 36: 59-63. (in Chinese)

[28] F Wang, W K Hou, S X Hu. Simulation system of gas shielded welding of melting electrode. Transactions of the China Welding Institution, 2003, 24: 35-39.

[29] W Wang, Z Wang, S Hu, et al. Weld pool surface fluctuations sensing in pulsed GMAW. Welding Research, 2017, 97: 327-337.

[30] XW Wang, Three-dimensional vision-based sensing of GTAW: A review. International Journal of Advanced Manufacturing Technology, 2014, 72: 333-345.

[31] W H Kim, S J Na. Heat and fluid flow in pulsed current GTA weld pool. International Journal of Heat and Mass Transfer, 1998, 41: 3213-3227.

[32] K Zhang, Y M Zhang, J S Chen, et al. Observation and analysis of threedimensional weld pool oscillation dynamic behaviors. Welding Research, 2017, 96: 143s-153s.
[33] C K Li, Y Shi, Y F Gu, et al. Monitoring weld pool oscillation using reflected laser pattern in gas tungsten arc welding. Journal of Materials Processing Technology, 2018, 255: 1-19.

[34] J K Huang, M H Yang, J S Chen, et al. The oscillation of stationary weld pool surface in the GTA welding. Journal of Materials Processing Technology, 2018, 256: 57-68.

[35] Y H Xiao, G D Ouden. A study of GTA weld pool oscillation. Welding Research Supplement, 1990: 289-293.

[36] S Q Zhang, S S Hu, Z J Wang. Weld penetration sensing in pulsed gas tungsten arc welding based on arc voltage. Journal of Materials Processing Technology, 2016, 229: 520-527.

[37] K Andersen, G E Cook, R J Barnett, et al. Synchronous weld pool oscillation for monitoring and control. IEEE Transactions on Industry Applications, 1997, 33: 464-471.

[38] C D Sorensen, TW Eagar. Modeling of oscillations in partially penetrated weld pools. Journal of Dynamic Systems, Measurement, and Control, 1990, 112: 469-474

[39] A J R Aendenroomer, G D Ouden. Weld pool oscillation as a tool for penetration sensing during pulsed GTA welding. Welding Journal, 1998, 77: 181s-187s.

[40] J B Ju, H Hasegawa, Y Suga. Oscillation of molten pool by pulsed assist gas oscillating method and penetration control using peculiar frequency. Journal of High Temperature Society, 2004, 30: 263-269.

\section{Submit your manuscript to a SpringerOpen ${ }^{\odot}$ journal and benefit from:}

- Convenient online submission

- Rigorous peer review

- Open access: articles freely available online

- High visibility within the field

- Retaining the copyright to your article

Submit your next manuscript at $\boldsymbol{\nabla}$ springeropen.com 